\title{
0 conceito de espiritualidade e sua interface com a religiosidade e a Psicologia Positiva
}

\author{
Luciana Fernandes Marques`
}

\section{Resumo}

Este é um estudo de cunho teórico que visa oferecer uma revisão de estudos científicos atuais sobre o conceito de espiritualidade e propor alguns apontamentos para futuras investigações. Para isso, traz uma revisão da literatura relacionada ao tema, de variadas áreas inclusive da Psicologia Positiva. Foram examinados artigos e livros em português, espanhol e inglês e foi realizada uma busca computadorizada no Portal SciELO (www.scielo.br) e no indexador eletrônico Scholar Google, bem como a partir das referências dos materiais examinados. Os descritores foram: conceit, espirit, religi; e seus correspondentes em espanhol e inglês. $\mathrm{O}$ objetivo desta revisão é delinear algumas definições que estabeleçam limites e contribuam na condução das pesquisas, quando o pesquisador deve optar por construtos e instrumentos de medida. São comentados alguns autores clássicos como Wundt, Maslow e James. Após há uma diferenciação sobre a religiosidade e a espiritualidade, discutindo suas semelhanças e os antagonismos que mais aparecem na literatura revisada e como o conceito de espiritualidade aparece na Psicologia Positiva.

Palavras-chave: espiritualidade, religiosidade, psicologia positiva

\section{Abstract}

This is a theoretical study that aims to provide a review of current scientific studies on the concept of spirituality and proposes some issues for future research. The article brings a literature review on the subject, including several areas of positive psychology. Articles and books in Portuguese, Spanish and English were examined

- Psicóloga, professora adjunto da Faculdade de Educação, Universidade Federal do Rio Grande do Sul (UFRGS, Porto Alegre, Brazil). E-mail: lucianafm@terra.com.br 
and held a computerized search in the SciELO (www.scielo.br) and electronic Indexer Google Scholar, and the references of materials examined. The descriptors were: conceit, espirit, religion, and their counterparts in Spanish and English. The purpose of this review is outline some definitions to set limits and help in conducting research when the researcher should choose constructs and measurement instruments. Comment some classical authors such as Wundt, Maslow and James. After there is a difference about religion and spirituality, discussing their similarities and antagonisms that are mentioned in the reviewed literature and how the concept of spirituality appears in Positive Psychology.

Key Words: spirituality, religiosity, positive psychology 


\section{Introdução}

Este é um estudo de cunho teórico que visa oferecer uma revisão sucinta e seletiva de estudos científicos atuais sobre a conceituação da espiritualidade e propor alguns apontamentos para futuras investigações. É improvável que qualquer definição única desse construto rico e complexo satisfaça, no entanto são necessárias algumas definições que provenham limites e organizem a literatura (Pargament \& Mahoney, 2002). Para isso, este artigo traz uma revisão da literatura relacionada ao tema, explorando os principais tópicos presentes nas diferenciações de espiritualidade e religiosidade e discorrendo sobre a visão da espiritualidade na psicologia positiva. Foram examinados artigos e livros em português e inglês e foi realizada uma busca computadorizada no Portal SciELO (www.scielo.br) e no indexador eletrônico Scholar Google, bem como a partir das referências dos materiais examinados. Os descritores foram: conceit, espirit, religi; e seus correspondentes em inglês.

Tanto a religião quanto a espiritualidade possuem uma longa tradição de estudos científicos, embora essa evolução tenha se dado de uma forma relativamente isolada das principais correntes das ciências médicas e do comportamento (Miller \& Thoresen, 2003). Quando surgiu a Psicologia da Religião, na década de 1880, associada a nomes como Starbuck, Wundt, James, Leuba, Freud, Jung e outros, era um campo de estudos suspeito (Avila, 2007). Encontramos a críticas o campo de estudos tanto por ser irreligioso quanto por ser confessional. Não havia um consenso e o objetivo de se estudar o fato religioso por parte da psicologia só seria elucidado por volta dos anos 1960 quando surgiu o enfoque "psicologia e religião" (Parsons \& Jonte-Pace, 2001).

Entre os precursores, que a sua vez é pouco conhecido mencionaremos a Wundt quem devotou uma parte substancial do seu trabalho à Psicologia da Religião (Belzen, 2005). Ao longo de alguns volumes sobre mitos e religião fundamentava a origem da religião em processos emocionais, principalmente $o$ medo (Ávila, 2007). E considerava curioso que os acadêmicos não estudassem esses temas. Dizia que não é que estivessem muito ocupados, ou que estivessem se dedicando a temas mais importantes, mas simplesmente porque estavam tão envolvidos com estudos elementares e preliminares (principalmente fisiológicos) que não tinham tempo para investigar a alma e estudar a origem do mito e do desenvolvimento da religiosidade a partir de novos métodos e perspectivas psicológicos (Belzen, 2005).

O termo espiritualidade tem uma longa e variada carreira na psicologia tendo como um dos principais expoentes William James que considerou a religião como sentimentos, atos e experiências do homem individual na sua solidão em relação a algo que considere como divino (Miller e Thoresen 2003). Essa definição, em 
essência, equaciona a religião como espiritualidade e ignora a religião institucional. No entanto, James (1995) considerou dois tipos básicos de religião: a religião institucional e a pessoal, mas se deteve mais no estudo da segunda e considerava que o núcleo da vida religiosa está nas experiências religiosas individuais (Dantas, Pavarin e Dalgalarrondo, 1999).

Conforme Hall e Lindzey (1984), Jung foi um dos psicólogos mais citados nas ciências das religiões, por ter realizado muitos estudos sobre representações arquetípicas nas religiões e mitos. Jung (1986) justificava a importância do estudo da psique em função do sofrimento ocasionado pelo abandono da religião e pela falta de direção espiritual. Considerava que esse acesso se daria no trabalho com o inconsciente, mas chegou a questionar se o homem estaria disposto a lançar-se no desconhecido da espiritualidade transcendental, ou se manteria a infantilidade e a segurança numa religiosidade mais carola com substitutos de pais bondosos e confiáveis. Segundo ele, a psicologia ocidental considera que o espírito é uma função da psique que é a mentalidade do indivíduo e contrapõe a uma explicação oriental onde o espírito é um princípio cósmico não dual e não exatamente uma parte do indivíduo. Chegou a afirmar que só seria capaz de curar um indivíduo de meia-idade que recuperasse sua orientação espiritual frente à vida.

Maslow foi outro psicólogo que se interessou no estudo da espiritualidade. Ele não estava interessado nas formas mais religiosas e tradicionais de espiritualidade, mas sim em valores genuinamente espirituais (Elkins, Hedstrom, Hughes, Leaf \& Saunders, 1988). Dizia que o ser humano tem uma "necessidade cognitiva de compreender" e por isso precisa de uma estrutura de valores, uma filosofia de vida, uma religião ou um substituto da religião para pautar sua vida (Maslow, s/d). Ele considerava que esses valores possuíam uma base inata, biológica e genética e sugeriu que fossem estudados junto com os objetivos mais elevados do ser humano, descobrindo quais são os valores aos que ser humano tende e quais são os que perdem quando ele adoece. Nesse sentido, tinha uma visão mais básica e discordante das formas tradicionais de expressão da espiritualidade, como a religião (Maslow, 1995).

O que parece evidente entre esses teóricos é o foco na experiência da espiritualidade, seja nas religiões ou fora delas. Outros psicólogos eminentes como Frankl, Allport, Rogers e Freud também se voltaram mais para a espiritualidade enquanto experiência individual do que para a religiosidade enquanto fenômeno institucionalizado e coletivo. Num estudo que parte dos conceitos clássicos como de Abraham Maslow, Carl G. Jung, William James e outros, o conceito de espiritualidade é considerado como uma dimensão da experiência humana que inclui certos valores, atitudes, perspectivas, crenças e emoções (Elkins, Hedstrom, Hughes, Leaf \& Saunders, 1988). Atualmente as pesquisas seguem interessadas pelos limites conceituais dos termos e suas implicações para a mensuração (esse 
tópico específico não será desenvolvido neste artigo) em variados contextos. Surgem ainda algumas discussões acerca da sobreposição dos termos espiritualidade e religiosidade e de algumas polaridades que são feitas ao separálos. A seguir uma revisão desses estudos.

\section{A espiritualidade e a religiosidade}

Muitos dos estudos revisados relacionam a espiritualidade com a religiosidade de alguma forma, seja separando de forma antagônica, seja unindo ambos como dois termos que se referem a um só conceito. Nesse sentido, se observa que a espiritualidade e a religiosidade possuem uma sobreposição inevitável, pois ambas se referem a experiências, sentimentos e inclinações muito próximos. Ambas envolvem a busca pela transcendência, o interesse pelo sagrado, a fé, etc. E podem ser cultivadas tanto de forma individual quanto coletiva, nas instituições religiosas ou fora delas. A freqüência da participação em cultos, a repetição de rituais e a crença em ritos são geralmente associadas à religiosidade. Já o cultivo do espiritual, valores, transcendência, fé, são considerados parte do fenômeno da espiritualidade que é encontrado em todas as culturas e todas as idades (Elkins, 1998). Nessa visão, a espiritualidade seria um conceito mais amplo, e a religiosidade um termo mais relativo a religiões específicas.

Algumas polaridades são encontradas nos estudos, como por exemplo, espiritualidade referindo-se a um aspecto mais individual e religiosidade ao contexto social (Mattis \& Jagers, 2001). Lukoff (1992) também separa os termos dessa forma, afirmando que a religiosidade é uma adesão a crenças e práticas de uma religião, igreja ou instituição, e a espiritualidade é uma relação pessoal com algo considerado como superior, divino, sagrado. Esses são antagonismos que surgem e polarizam o objeto de estudo buscando comparar e diferenciar campos de estudo, mas em função da inevitável sobreposição, o que é comum a ambas pode acabar perdendo-se.

Em relação a considerar-se a religiosidade mais voltada para o social, a crítica de que o ser humano não vive só, e a espiritualidade também não surge de forma isolada, e pode ser comum ao grupo familiar e ser um fenômeno coletivo. Essa separação torna-se falsa quando observamos que tanto a religiosidade quanto a espiritualidade se referem ambas a esferas individuais assim como a esferas coletivas. A fé e o desenvolvimento de crenças se formam a partir do convívio e dos relacionamentos que se estabelece desde a infância (Fowler, 1992) e para muitas pessoas, só tem sentido desenvolver sua religiosidade ou sua espiritualidade, se for de uma forma isolada.

Na literatura revisada, por vezes, parece que o interesse em diferenciar os termos atende a uma demanda, que é uma questão permanente aos investigadores: 
é possível a pessoa ser espiritualizada e não ser afiliada a nenhuma religião? Elkins et al. (1988) dizem que sim. Inclusive as pessoas se descrevem dessa forma nos estudos. Como afirma Fuller (2001) no seu livro Spiritual but not religious, as pessoas que assim se descrevem não freqüentam templos, não possuem uma afiliação religiosa, mas seguem algumas práticas espirituais e cultivam certos valores de forma privada. Poderíamos indagar de onde surgiram essas práticas espirituais e se elas têm uma origem em alguma religião. Pois ainda que as pessoas cultivem práticas espirituais, sem vínculo com uma religião específica, podem trazer no arcabouço das próprias práticas uma religiosidade embutida. Uma explicação do autor para esse fenômeno de valorização do espiritual separado do religioso consiste na pouca relevância da religião na vida das pessoas, e na força da ciência como forma de compreender o mundo. Conforme estudo de Shahabi et al. (2002), aqueles que se auto-denominam como unicamente espirituais são jovens, provavelmente mulheres e com maior nível de escolaridade. Aqueles que se identificam como somente religiosos são mais julgadores, mais rígidos nas suas crenças, e mais intolerantes com outros grupos, inclusive com aqueles que não são nem religiosos, nem espirituais.

Ao considerar a espiritualidade como diferente da religiosidade, abre-se um campo de atuação profissional fora das religiões. Afinal, ao vincular espiritualidade e religiosidade, corre-se o risco de perder um âmbito de atuação na Psicologia, Educação, Medicina e outras. Sendo a espiritualidade uma nova arena no campo científico, desvinculada da religião, surge a possibilidade de legitimar campos de aplicação de abordagens não religiosas em tratamentos terapêuticos, experiências da consciência, etc., de um ponto de vista técnico-científico. E é exatamente para essa direção que se encaminham os estudos da interface do conceito de espiritualidade com a saúde como se pode ver em Miller (1999) e Zinnbauer e Pargament (2000). Alguns desses autores também se preocuparam em localizar os principais componentes da espiritualidade no sentido de validar o construto e poder mensurar e dar respaldo científico para a aplicação desse conhecimento.

Nessa diferenciação e separação entre espiritualidade e religiosidade, surgiu outro viés que é o da pureza da espiritualidade e da malevolência da religião (Hill \& Pargament, 2003), talvez para justificar que não seria um retorno a não diferenciação entre ciência e religião. A religiosidade parece menos promissora como objeto de estudo e passa a ser associada a dogmas, crendices e perda da liberdade do fiel. Já a espiritualidade parece uma promessa de autonomia e de genuíno desenvolvimento interior sem interferência externa. Alguns contextos e ambientes, a religiosidade poderá favorecer apoio social e diminuição de condutas insalubres como os abusos do álcool como apontam Koenig et al. (1994) no seu estudo, quando constatam que pessoas com maior freqüência religiosa e mais envolvidas com preces apresentam menores índices de alcoolismo. Estudos 
anteriores como o de Cohen e Wills (1985) também já haviam demonstrado a importância do suporte religioso como uma forma de suporte social que pode ser um recurso para auto-estima, informação, companhia e ajuda contra estressores.

Ainda nessa separação bom-ruim, alguns autores têm investigado formas de religiosidade patológica como fuga da realidade e acirramento de conflitos entre culturas (Hill et al., 2000), e também efeitos negativos da religiosidade como sentimento de culpa, ansiedade, intolerância, depressão, rigidez cognitiva e excessiva dependência (Miller \& Thoresen, 2003). Há que se pontuar que a religião em si não é boa ou má, mas sim o uso que se faz dela. Ainda assim, esses estudos não são suficientes para se concluir que todas as formas de viver e experienciar a religião estão atreladas a elementos negativos.

Miller e Thoresen (2003) adotam um ponto de vista similar, separando o conceito de espiritualidade e o de religiosidade. Relacionam a espiritualidade com o âmbito das experiências humanas, e a religiosidade com domínios institucionais religiosos. Consideram que a religiosidade está necessariamente relacionada à religião, enquanto a espiritualidade pode estar vinculada ou não. Entretanto, Hill et al. (2000) afirmam que espiritualidade e religião, ao invés de conceitos independentes, são construtos relacionados. E o principal denominador comum é o sagrado que representa o destino mais vital buscado tanto pela pessoa religiosa quanto pela espiritualizada (Hill \& Pargament, 2003).

Zinnbauer e Park (2005) relatam que há algum tempo, os termos eram indiferenciados, mas com o avanço da modernidade, declínio das instituições religiosas tradicionais e o incremento das formas individuais de expressão da fé iniciaram um movimento de ênfase na experiência direta do sagrado. Com esse movimento, um acirramento das diferenças entre a religiosidade e a espiritualidade. Os autores revisaram definições sobre os termos e classificaram em algumas polarizações em torno da separação religiosidade e espiritualidade:

a) Religião substantivo e espiritualidade funcional: a espiritualidade representando esforços em direção a uma variedade de objetivos sagrados e existenciais; e a religiosidade usada como um substantivo associado a crenças formais, práticas grupais e instituições.

b) Religião estática e espiritualidade dinâmica: o termo religiosidade descrevendo o que é a religião e não o que ela faz ou como ela trabalha, e a espiritualidade como um termo associado a verbos ligados a movimento, fluidez.

c) Religião institucional objetiva e espiritualidade pessoal subjetiva: a religiosidade se referindo a algo institucional, organizado e social e a espiritualidade ligada a algo pessoal, transcendente, de interconexão.

d) Religião baseada em crença - espiritualidade baseada na experiência: religiosidade seria mais dogmática e teológica e a espiritualidade referente aos valores do Self. 
e) Religião negativa - espiritualidade positiva: a espiritualidade como algo leve, de elevados potenciais humanos, com estados afetivos positivos, e a religiosidade mais voltada para dogmas, padres, doutrinas antigas e igrejas.

A partir dessa revisão de literatura, Zinnbauer e Park (2005) reuniram em dez principais conclusões acerca das definições de religiosidade e espiritualidade:

1) a religiosidade e a espiritualidade são fatos culturais não redutíveis a outros processos ou fenômenos;

2) a maioria das pessoas se define como sendo os dois, religiosa e espiritualizada;

3) uma minoria identificável se diz espiritualizada, mas não religiosa e usa a espiritualidade no sentido de rejeitar a religião;

4) religiosidade e espiritualidade se sobrepõe consideravelmente na população americana e esses construtos são relacionados mas não idênticos;

5) religiosidade e espiritualidade são termos complexos e multidimensionais;

6) tanto a religiosidade quanto a espiritualidade podem estar associadas em si saúde mental como ao estresse emocional;

7) existem aspectos substantivos e funcionais tanto na religiosidade quanto na espiritualidade;

8) religiosidade e espiritualidade são construtos multi-níveis, se relacionam ao fenômeno biológico, afetivo, cognitivo, moral, relacional, da personalidade ou da auto-identidade, social, cultural e global;

9) religiosidade e espiritualidade podem desenvolver e mudar com o passar do tempo nos indivíduos e grupos;

10) religiosidade e espiritualidade têm adquirido diferentes conotações conforme seu uso, religiosidade sendo mais associada a um nível de análise social e grupal e espiritualidade mais associado a um nível de análise individual.

Outra vertente de estudos associa os dois termos num conceito só se referindo à religiosidade/espiritualidade como uma dimensão importante no enfrentamento de situações adversas (Ironson, Stuetzle \& Fletcher, 2008; Park, 2007; MoreiraAlmeida, Lotufo-Neto \& Koenig, 2006; Panzini \& Bandeira, 2005; Samano et al., 2004; Pargament \& Mahoney, 2002). Nessa linha de pensamento, consideram que os construtos se sobrepõem e usam apenas o termo espiritualidade num sentido mais amplo incluindo religiosidade. Quando se referem aos aspectos institucionais exclusivamente, usam o termo religião. Pargament e Mahoney (2002) adotam essa visão considerando a espiritualidade como a busca pelo sagrado que inclui Deus, o divino, o transcendente de onde emana uma força; inclui objetos sagrados (igrejas, templos), eventos e transições (nascimento, morte), aspectos materiais (vinho, cruz), produtos culturais (música, literatura), pessoas (santos, líderes), atributos 
psicológicos (self, significado), atributos sociais (compaixão, comunidade) e papéis (casamento, parentesco, trabalho). A pessoa seria considerada espiritualizada na medida da extensão do seu interesse em buscar, conhecer ou experienciar algo relacionado ao que ela considere como sagrado.

Numa sondagem visando mensurar a importância da religião e da espiritualidade na vida dos americanos, Gallup e Lindsay (1999) encontraram uma tendência a definir religião como fatores institucionais, ou seja, um fiel, com freqüência de participação em culto, afiliação religiosa, acreditar em Deus, milagres, vida após a morte, bíblia, oração e leitura da bíblia. Se esse estudo tivesse se realizado em outros países com outras culturas, é provável que alguns conceitos fossem diferentes. Então um aspecto a se considerar quando se estuda espiritualidade e religiosidade é o que diz respeito à universalização do conceito (Roehlkepartain, Benson, King \& Wagener, 2006) e o risco de aplicá-lo de forma indiscriminada a diferentes culturas, faixas etárias e situações de vida. Se poderia imaginar que num cenário de maior pluralidade religiosa (como no Brasil) se encontraria maior diversidade de sentidos dados a esses termos. Talvez cada investigação pudesse contar com uma parte mais qualitativa onde esse significado pudesse emergir. Uma parte das investigações voltada a ouvir o participante da pesquisa na sua visão talvez revele que as definições operacionais científicas são diferentes da visão das pessoas estudadas. Os cientistas estão mais preocupados com construtos não diretamente observáveis (Miller \& Thoresen, 2003) e fundamentados por uma rede de comunidades científicas, do que com as percepções das pessoas sobre sua experiência e sobre o conceito em si. Mas parece salutar uma complementaridade entre medidas psicométricas testadas e usadas em estudos multiculturais e entre o aprofundamento do significado dessa dimensão conforme o público estudado.

\section{A espiritualidade na Psicologia Positiva}

A Psicologia Positiva é um termo guarda-chuva que abriga teorias e pesquisas sobre o que faz valer a pena viver (Seligman \& Csikszentmihalyi, 2000). São teorias e investigações voltadas para a saúde, emoções positivas, bem-estar, felicidade, virtudes e forças do caráter. Conforme Yunes (2003), a Psicologia Positiva é um movimento que se afirmou a partir de uma edição especial do periódico “American Psychologist” em 2001, onde ficou claro que se tratava de uma visão mais aberta e apreciativa dos potenciais e virtudes humanas. Seligman (2004) confirma que o início da Psicologia Positiva ocorreu em janeiro de 1998 a partir da sua iniciativa junto com outros renomados cientistas como Mihaly Csikszentmihalyi, Ray Fowler, Chris Peterson, George Vaillant, Ed Diener dentre outros, interessados em desenvolver pesquisas usando o método quantitativo a fim 
de promover uma mudança no foco da Psicologia atual. Embora o termo Psicologia Positiva tenha assumido mais recentemente uma nova conotação, ele compartilha um rico legado com o humanismo, com a psicologia da saúde, construtivismo e estudos espirituais (Mahoney, 2002). Essa mudança na visão é importante, conforme Mahoney (2002), em função das suas implicações para futuras teorias, pesquisas e prática, bem como uma possibilidade de mudança na imagem da psicologia e na sua aplicação cotidiana. Trata-se basicamente da visão de ser humano, que costumava estar assentada em motivos egoístas e impulsivos e que agora passa a acolher a bondade e altruísmo (Seligman, 2004). Naturalmente não se trata de romantizar a visão de ser humano, ou de sair de um pólo negativo da psicologia para outro extremo, totalmente positivo, mas sim de reconhecer que essas forças e fortalezas existem e estão operando.

Conforme Seligman (2002), a mensagem do movimento da Psicologia Positiva é lembrar que o nosso campo teórico está deformado. A psicologia não é somente o estudo da doença e do dano, mas também da força e da virtude, e também não se refere somente a doença e saúde, mas a trabalho, educação, insight, amor, crescimento. No seu livro Felicidade Autêntica (Seligman, 2004) conta a história de quando se tornou presidente da APA (American Psychological Association) e pensou em qual seria sua missão. Antes de lançar a idéia da Psicologia Positiva, havia percebido que talvez não devesse ter se concentrado tanto no estudo dos cães que desistiam ao levar choque, cuja pesquisa foi a base da teoria do desamparo aprendido. Mas sim, naqueles poucos que não desistiam de tentar, que pareciam crer que algo iria mudar. Ou seja, nos que não adoeciam, nem se tornavam apáticos a despeito do estímulo aversivo.

Averill (2002), no entanto, chama a atenção para o fato de que ao concentrar-se na saúde e no bem-estar psicológico, a Psicologia Positiva não pressupõe ausência de sofrimento, mas sim engajamento ativo no mundo, sentido e propósito na vida, conexão com pessoas e objetos além de si mesmo. Seria como adotarmos como consenso que o sofrimento está ali, mas apesar dele se pode crescer e florescer como ser humano. Conforme Park, Peterson e Seligman (2003) as fortalezas do caráter e as experiências positivas são um tema central da Psicologia Positiva sendo que essas fortalezas podem ser definidas como traços positivos refletidos nos pensamentos, sentimentos e comportamentos e existem em graus que podem ser mensurados de acordo com diferenças individuais. As emoções positivas criam recursos pessoais de enfrentamento a certas situações que se apresentam na vida e fortalecem os repertórios físicos, sociais e intelectuais (Fredrickson, 2001). Essa teoria pretende construir e avançar no conhecimento sobre aspectos virtuosos e positivos como a esperança, criatividade, coragem, sabedoria, espiritualidade e felicidade que podem atuar como fatores protetores e preventivos (Paludo e Koller, 2007). 
Mas a Psicologia Positiva não estuda apenas esses temas sob uma determinada perspectiva (a perspectiva da saúde), mas também se interessa pelas condições e processos que contribuem para o florescimento e ótimo funcionamento das pessoas, grupos e instituições (Gable \& Haidt, 2005). Paludo e Koller (2006) concordam que essa teoria e pretendem contribuir com o florescimento e o funcionamento saudável das pessoas, grupos e instituições, preocupando-se em fortalecer competências ao invés de corrigir deficiências. Nessa abordagem das fortalezas, Peterson \& Seligman (2003) contam que não havia interesse em estudar apenas as virtudes valorizadas pelos protestantes norte-americanos do século XIX ou pelos brancos, acadêmicos, de meia-idade, do sexo masculino, do século $\mathrm{XX}$, mas sim algo mais amplo. Por isso, partiram para uma análise dos textos básicos de várias das principais religiões e tradições filosóficas orientais e ocidentais, passando por Aristóteles e Platão, Santo Tomás de Aquino e Santo Agostinho, O velho Testamento e o Talmude, Confúcio, Buda, Lao Tze, o Código Samurai, o Alcorão, Benjamin Franklin e os Upanishads e perceberam a constância de seis virtudes: sabedoria, coragem, humanidade, justiça, temperança e transcendência (Seligman, 2004).

E para o desenvolvimento dessas virtudes, há vários caminhos distintos que conduzem que são as forças de caráter, ou forças pessoais (Seligman, 2004; Peterson \& Seligman, 2003). Na Psicologia Positiva, o termo espiritualidade aparece citado como uma força pessoal e que junto com outros aspectos virtuosos (como: apreciação da beleza e excelência, gratidão, esperança e humor) levam à virtude da transcendência (Peterson \& Seligman, 2003). Park e Peterson (2006) consideram a espiritualidade uma das mais sofisticadas forças de caráter, junto com capacidade de perdoar e abertura mental. Conforme Averill (2002), essas características ajudam a definir a dimensão espiritual da experiência humana e também presumem habilidade para ser criativo, emocional e intelectualmente. Além dessa conexão com outras forças, como com os aspectos emocionais e intelectuais, a espiritualidade aparece em estudos associada a comportamentos pró-sociais, como gratidão e empatia (Paludo e Koller, 2007). Seligman (2004) comenta que a religião foi alvo de críticas na época de Freud, por produzir culpa, repressão da sexualidade, intolerância, antiintelectualismo e autoritarismo. Mas há uns 20 anos surgiram dados sobre os efeitos psicológicos positivos da fé que geraram uma força oposta e cita: pessoas religiosas são menos propensas a usar drogas, a se divorciar, a cometer crimes e suicídio, são fisicamente mais saudáveis, vivem mais, resistem mais à depressão, são mais felizes e mais satisfeitos com a vida do que os não religiosos. O autor recupera a discussão ocorrida na época do behaviorismo do que explicaria essa associação, e a resposta era o apoio social. Seligman (2004) pondera, no entanto, afirma que talvez o que da origem a essas associações seja a esperança no futuro e o significado de vida encontrado nas 
religiões: “A relação entre esperança no futuro e fé religiosa é provavelmente a pedra angular do motivo pelo qual a fé afugenta o desespero e aumenta a felicidade (p. 78)”.

A espiritualidade (assim como a religiosidade, fé e propósito) deve ter algumas características para ser considerada uma fortaleza do caráter: ter crenças coerentes sobre um alto-propósito e sentido do universo; compreender onde se encontra num esquema mais amplo das coisas; ter crenças sobre o significado da vida que moldam a conduta e provém conforto (Park e Peterson, 2006; Peterson \& Seligman, 2003). Essa força só se desenvolveria completamente a partir da adolescência, em função dessa complexidade.

As fortalezas constituem o princípio fundamental da condição humana e uma atividade congruente com elas representa um importante caminho rumo uma vida psicológica ótima (Martinez, 2006). Segundo Martinez (2006) a espiritualidade é uma força típica do grupo das virtudes transcendentais que permitem ao indivíduo estabelecer uma conexão com o universo proporcionando sentido à sua vida. Mais especificamente a espiritualidade se definiria como a crença e o compromisso com os aspectos transcendentais da vida, o divino, o sagrado, o universal e uma convicção na existência de uma dimensão transcendente (não material) na vida.

Seligman (2004) diferenciou espiritualidade de transcendência, optando por usar mais o segundo termo, já que o primeiro se referiria mais a designação da escolha (religiosa). Usando o termo transcendência esperava evitar a confusão entre espiritualidade, como uma força religiosa, e entusiasmo e gratidão, como forças não-religiosas desse mesmo grupo - o grupo da transcendência. Transcendência seria, para o autor, o grupo final de forças, que saem da pessoa e estabelecem conexão com algo maior e mais durável, como outras pessoas, o futuro, o divino, o universo. No seu teste que avaliam as 24 maiores forças pessoais, a $21^{\text {a }}$ força é Espiritualidade/senso de propósito/fé/religiosidade e estas são algumas das perguntas: "Você tem crenças sólidas e coerentes acerca do propósito maior e do significado do universo? Para você, as crenças dão forma às ações e são fonte de conforto? Você tem uma filosofia de vida articulada, religiosa ou não, que o situe no universo? Para você, o significado da vida está na ligação com algo maior? (Seligman, 2004, p. 176)”.

Outra abordagem da espiritualidade é encontrada num livro publicado recentemente sobre Psicologia Positiva de Snyder e Lopez (2007), mais especificamente no capítulo sobre Mindfulness, flow and spirituality. Conforme os autores, a maioria das pessoas passa pela vida de forma não-consciente, alheias às experiências, emoções e significados e sugerem uma psicologia para um viver mais profundo com aplicações universais que ensine as profundezas do contentamento, do desfrutar e da plenitude de significado que pode advir do engajamento na vida cotidiana. A espiritualidade, nesse sentido, aparece como uma 
atenção ao sagrado da vida e como um estado da mente que é de acesso universal. Para esses autores, há um consenso entre os pesquisadores de que a espiritualidade é um estado positivo da mente experimentado pela maioria das pessoas. Eles concordam que esse não e um conceito único, mas uma forma de abordar a questão devolvendo atenção plena, experiência de fluxo e sentimentos de significado à vida cotidiana.

Neste ano um volume inteiro do periódico Journal of Clinical Psychology foi especialmente dedicado à questão da mindfulness, ou atenção plena (tradução livre). Shapiro (2009), no artigo de introdução ao tema, aponta a integração da atenção plena ao campo da psicologia, já antecipando os desafios de traduzir as culturas orientais, não conceituais, não duais, paradoxais, para uma linguagem clínica, científica e acadêmica ocidental. O termo atenção plena é freqüentemente associado ao budismo e é tanto um processo quanto um produto (se é que se pode mencionar nesses termos) da meditação. Caminhos espirituais religiosos e não religiosos por vezes englobam práticas desse cunho.

\section{Considerações Finais}

Como foi dito no início deste artigo, é improvável que qualquer definição única desse construto rico e complexo satisfaça. São muitas as teorias e pressupostos envolvidos e a cada estudo, surgem novos objetivos, novas dificuldades, novos instrumentos, novas parcerias o que tornaria contraproducente uma definição cabal. No entanto, alguns contornos e operacionalização de conceitos são necessários para se poderem efetuar comparações entre grupos e culturas. Certos consensos já estão presentes como se pode ver na revisão acima, mas ainda tratase de uma área um pouco hermética e de difícil acesso em função da sua inefabilidade. Ainda não se encontra na literatura uma conceituação e diferenciação dos componentes da espiritualidade e da religiosidade e mesmo uma maior delimitação e aprofundamento de conceitos específicos como: fé, crenças, valores, sentido de vida, transcendência, devoção, conversão, sabedoria, experiência mística, entre outros envolvidos na temática. Os avanços nos métodos investigativos têm mitigado essas dificuldades e longe de estar mais próximo de respostas fechadas, têm se aproximado mais do fenômeno e observado suas interconexões na saúde e na educação. A Psicologia Positiva se mostra um espaço promissor e privilegiado de estudo da espiritualidade sob a ótica do florescimento humano, aliando rigor metodológico com uma proposta otimista e corajosa sobre as fortalezas humanas. 


\section{Referencias}

Averill, J. R. (2002). Emotional creativity: toward "spiritualizing the passions. In C. R. Snyders \& S. J. Lopez (Eds.) Handbook of Positive Psychology. (p.172-188). Oxford: Oxford University Press.

Avila, A. (2007). Para conhecer a Psicologia da Religião. São Paulo, Edições Loyola.

Belzen, J. A. (2005). Methodological concerns in the psychology of religion: continuities, losses and transforming perspectives. Religion, 35, 137-165.

Cohen, S. \& Wills, T. A. (1985). Stress, social support, and the buffering hypothesis. Psychological Bulletin. 98(2), 310-357.

Dantas, C. R.; Pavarin, L. B.\& Dalgalarrondo, P. (1999). Sintomas de conteúdo religioso em pacientes psiquiátricos. Revista Brasileira de Psiquatria, 21 (3), 158-164.

Elkins, D. (1998). Além da religião. São Paulo: Pensamento.

Elkins, D. N.; Hedstrom, L. J.; Hughes, L. J.; Leaf, J. A. \& Saunders, C. (1988). Toward a humanistic-phenomenological spirituality, definition, description and measurement. Journal of Humanistic Psychology, 28 (4), 5-18.

Fowler, J. (1992). Estágios da fé: a psicologia do desenvolvimento humano e a busca de sentido. São Leopoldo: Sinodal.

Fredrickson, B. L. (2001). The role of positive emotions in positive psychology: the broaden-and-built theory of positive emotions. American Psychologist, 55, 218226.

Fuller, R. C. (2001). Spiritual, But Not Religious: Understanding Unchurched America. New York: Oxford University Press.

Gable, S. L. \& Haidt, J. (2005). What (and why) is Positive Psychology? Review of General Psychology, 9 (2), 103-110.

Gallup, G., Jr., \& Lindsay, D. M. (1999). Surveying the religious landscape: Trends in U.S. beliefs. Harrisburg: Morehouse.

Hall, C.; Lindzey, G. (1984). Teorias da personalidade. São Paulo: EPU.

Hill, P. C. \& Pargament, K. (2003). Advances in the conceptualization and measurement of religion and spirituality, implication for physical and mental health research. American Psychologist, 58 (1), 64-74. 
Hill, P. C.; Pargament, K. I.; Hood, R. W.; Jr., McCullough, M. E.; Swyers, J. P.; Larson, D. B., \& Zinnbauer, B. J. (2000). Conceptualizing religion and spirituality: points of commonality, points of departure. Journal for the theory of social behaviour, 30, 51-77.

Ironson, G.; Stuetzle, R \& Fletcher, M. A. (2006). An increase in religiousness/ spirituality occurs after HIV diagnosis and predicts slower disease progression over 4 years in people with HIV. Journal of General Internal Medicine, 21 (5), 62-68.

James, W. (1995). As variedades da experiência religiosa. São Paulo: Cultrix.

Jung, C. G. (1986). Psicologia e Religião Oriental. Petrópolis: Vozes.

Koenig, H.G.; George, L.K.; Meador, K.G.; Blazer, D.G.; Ford, S.M. (1994). Religious practices and alcoholism in a southern adult population. Hospital and Community Psychiatry, 54 (3): 225-231.

Lukoff, D. (1992). Toward a more culturally sensitive DSM-IV (psychoreligious and psuchospiritual problems). The Journal of Nervous and Mental Disease, 180, 673-682.

Mahoney, A. (2002).Constructivism and Positive Psychology. In C. R. Snyder, \& S. J. Lopez (Eds.), Handbook of Positive Psychology (pp. 745-750). New York: Oxford University Press.

Martinez, M. L. (2006). El estudio científico de las fortalezas trascendentales desde la psicología positiva. Clínica y Salud, 17 (3), 245-258.

Maslow, A. H. (s/d). Introdução à psicologia do ser. Rio de Janeiro: Eldorado.

Maslow, A. H. (1995). El hombre autorrealizado. Barcelona: Kairós.

Mattis, J. S.; Jagers, R. J. (2001). A relational framework for the study of religiosity and spirituality in the lives of African Americans. Journal of Community Psychology, 29 (5), 519-539.

Miller, W. (1999). Integrating Spirituality Into Treatment: Resources for Practitioners. Washington: American Psychological Association.

Miller, W. R. \& Thoresen, C. E. (2003). Spirituality, religion and health: An emerging research field. American Psychologist, 58 (1), 24-35.

Moreira-Almeida, A.; Lotufo Neto, F. \& Koenig, H. G. (2006). Religiousness and mental health: a review. Revista Brasileira de Psiquiatria, 28 (3), 242-250.

Paludo, S. S. \& Koller, S. H. (2006). Gratidão em contextos de risco: uma relação possível? Revista Psicodebate Psicología, Cultura y Sociedad, 7, 55-66. 
Paludo, S. S. \& Koller, S. H. (2007). Psicologia Positiva: uma nova abordagem para antigas questões. Paidéia, 17 (36), 9-20.

Panzini, R. G. \& Bandeira, D. R. (2005). Escala de coping religioso-espiritual (Escala CRE): elaboração e validação de construto. Psicologia em estudo, 10 (3), 507-516.

Pargament, K. I; Mahoney, A. (2002). Spirituality: the discovery and conservation of the sacred. In C. R. Snyder \& S. J. Lopez (Ed.) Handbook of Positive Psychology. (p. 646-659) New York: Oxford University Press.

Park, C. L. (2007). Religiousness/spirituality and health: a meaning systems perspective. Journal of Behavioral Medicine, 30 (4), 319-328.

Park, N. \& Peterson, C. (2006). Character strengths and happiness among young children: content analysis of parental descriptions. Journal of Happiness Studies, 7, 323-341.

Park, N.; Peterson, C. \& Seligman, M. E. P. (2004). Strengths Of Character And Well-Being. Journal of Social and Clinical Psychology, 23 (5), 603-619.

Parsons, W. B. \& Jonte-Pace, D. (2001). Religion and psychology: mapping the terrain. London: Routledge.

Peterson, C. \& Seligman, M. E. P. (2003). Character strengths before and after September 11. Psychological Science, 14 (4), 381-384.

Roehlkepartain, E. C.; Benson, P.; King, P. E.; Wagener, L. M. (2006). Spiritual development in childhood and adolescence: moving to the scientific mainstream. In E. C. Roehlkepartain; P. L. King; L. M. Wagener, P. L. Benson (Ed.). The handbook of spiritual development in childhood and adolescence. (p. 1-15) Thousand Oaks: Sage.

Samano, E. S. T.; Goldenstein, P. T.; Ribeiro, L. M.; Lewin, F.; Valesin Filho, E. S.; Soares, H. P.; Giglio, A. (2004). Praying correlates with higher quality of life: results from a survey on complementary / alternative medicine use among a group of Brazilian cancer patients. São Paulo Medical Journal, 122 (2), 60-63.

Seligman, M. E. P. (2002). Positive psychology, positive prevention and positive therapy. In C. R. Snyders \& S. J. Lopez (Eds.) Handbook of Positive Psychology. (p.3-12). Oxford: Oxford University Press.

Seligman, M. E. P. (2004). Felicidade autêntica. Rio de Janeiro: Objetiva.

Seligman, M. E. P. \& Csikszentmihalyi, M. (2000). Positive psychology: An introduction. American Psychologist, 55, 5-14. 
Shahabi, L.; Powell, L. H.; Musick, M. A.; Pargament, K. I.; Thoresen, C. E.; Williams, D.; Underwood, L. \& Ory, M. A. (2002). Correlates of self-perceptions of spirituality in american adults. Behavioral Science, 24 (1), 59-68.

Shapiro, S. L. (2009). The integration of mindfulness and psychology. Journal of Clinical Psychology, 65 (6), 555-560.

Snyder, C. R. \& Lopez, S. J. (2007). Positive Psychology: the scientific and practical explorations of human strengths. Thousand Oaks: Sage.

Yunes, M. A. M. (2003). Psicologia positiva e resiliência: o foco no indivíduo e na família. Psicologia em Estudo, 8, 75-84.

Zinnbauer, B. J. \& Pargament, K. I. (2000). Working With the Sacred: Four Approaches to Religious and Spiritual Issues in Counseling. Journal of Counseling \& Development. 78 (2), 162-171.

Zinnbauer, B. J. \& Park, C. L. (2005). Religiousness and spirituality. In R. F. Paloutzian \& C. L. Park (Ed.) Handbook of psychology of religion and spirituality. (pp. 21-42). New York: The Guilford Pres. 
